\title{
Determinants of skilled birth attendants for delivery in Nepal
}

\author{
Baral YR, ${ }^{1}$ Lyons $\mathrm{K},{ }^{2}$ Skinner J, ${ }^{3}$ van Teijlingen $\mathrm{ER}^{4}$
}

\author{
${ }^{1-3}$ Faculty of Applied Social Sciences, \\ Ladbroke House, London Metropolitan \\ University, UK \\ ${ }^{4}$ Centre for Midwifery, Maternal \& Perinatal \\ Health, School of Health \& Social Care, \\ Bournemouth University, Bournemouth, UK
}

\section{Corresponding author}

Mr. Yuba Raj Baral

Faculty of Applied Social Sciences

Ladbroke House, London Metropolitan University, UK

Email: yrb0009@my.londonmet.ac.uk

Kathmandu Univ Med J 2010;8(31):325-32

\begin{abstract}
This review is to explore the factors affecting the uptake of skilled birth attendants for delivery and the issues associated with women's role and choices of maternal health care service for delivery in Nepal. Literature was reviewed across the globe and discussed in a Nepalese context. Delivery by Skilled Birth Attendance serves as an indicator of progress towards reducing maternal mortality worldwide, the fifth Millennium Development Goal. Nepal has committed to reducing its maternal mortality by $75 \%$ by 2015 through ensuring accessibility to the availability and utilisation of skilled care at every birth.

The literature suggests that several socio-economic, cultural and religious factors play a significant role in the use of Skilled Birth Attendance for delivery in Nepal. Availability of transportation and distance to the health facility; poor infrastructure and lack of services; availability and accessibility of the services; cost and convenience; staff shortages and attitudes; gender inequality; status of women in society; women's involvement in decision making; and women's autonomy and place of residence are significant contributing factors for uptake of Skilled Birth Attendance for delivery in Nepal.

The review found more quantitative research studies exploring the determinants of utilisation of the maternal health services during pregnancy in Nepal than qualitative studies. Findings of quantitative research show that different social demographic, economic, socio-cultural and religious factors are responsible for the utilisation of maternal health services but very few studies discussed how and why these factors are responsible for utilisation of skilled birth attendants in pregnancy. It is suggested that there is need for more qualitative research to explore the women's role and choice regarding use of skilled birth attendants services and to find out how and why these factors are responsible for utilisation of skilled birth attendants for delivery. Qualitative research will help further exploration of the issues and contribute to improvement of maternal health services.
\end{abstract}

\section{Key Words}

Asia, developing country, maternal health, pregnancy, skilled birth attendance

\section{INTRODUCTION}

Pregnancy and child birth complications are a leading cause of death and disability among women of reproductive age in the developing countries of the world. A bibliometric study in Nepal shows that more research was published using a quantitative approach than other methods to describe the issues associated with maternity care and uptake of SBAs. ${ }^{2}$ The presence of a skilled birth attendant is important for averting maternal morbidity and mortality. The World Health Organization (WHO) defines a skilled birth attendant (SBA) as "an accredited health professionalsuch as a midwife, doctor or nurse- who has been educated and trained to proficiency in the skills needed to manage normal(uncomplicated) pregnancies, childbirth and the immediate postnatal period, and in the identification, management and referral of complications in women and newborns".3
In September 2000 the members of the United Nations (UN) adopted the Millennium Declaration and set eight millennium development goals, one of which is reducing maternal mortality. ${ }^{4}$ Delivery by SBAs serves as an indicator of progress towards reducing maternal mortality worldwide and is the fifth Millennium Development Goal (MDG). Use of SBAs during pregnancy, labour and delivery during the postpartum period could prevent many instances of maternal morbidity and mortality. Unfortunately, qualified midwives, nurses and doctors are often not available in the rural areas of many developing countries where most women are delivered. ${ }^{5}$

Although all women and babies need pregnancy care, care in childbirth is most important for the survival of pregnant women. ${ }^{2}$ However, around the world, one third of births take place at home without the assistance of a skilled attendant. ${ }^{6}$ The WHO strongly advocates for "skilled 
care at every birth" to reduce the global burden of 536, 000 maternal deaths every year. ${ }^{7}$ There are still 3 million stillbirths and 3.7 million newborn deaths each year. ${ }^{8}$

According to the Nepal Demographic Health Survey (NDHS 2006) maternal mortality ratio of Nepal (MMR) has reduced from 539 to 281 per 100,000 live births from 2001 to $2006 .{ }^{9}$ Despite these measured improvements $81 \%$ of women still give birth at home without the presence of skilled birth attendants. ${ }^{8,10}$ The data derived from different sources from 1996 until 2010 suggests that Nepal may be achieving this goal. However, only one in five women in Nepal has a SBA to help at the riskiest moment in their reproductive life. ${ }^{9}$

\section{METHODS}

The main aim of this paper is to review the available literature to identify the issues associated with women's role and choices regarding use of SBAs and to explore factors affecting utilisation of maternal health services in Nepal. Published and unpublished studies produced between 1998 to May 2010, and other reports related to Nepal were searched. To identify the studies electronic data bases such as Medline, CINAHL, EMBASE, Science Direct and Scopus were searched. WHO websites and Health Ministry of Nepal (MoHN) websites were searched and hand searching of relevant reference including international papers was also included in the review and related to the Nepalese context.

Skilled Birth Attendants and Millennium Development Goals, Nepal

The Ministry of Health in Nepal has committed to improve maternal morbidity and mortality rates. Most recently, high priority has been given to the National Safe Motherhood Programme (NSMP) within the Nepal Health Sector Strategy Plan. The Nepal health sector has set a goal of meeting the 5 years plan/Poverty Reduction Strategy Plan and MDG to reduce the MMR by $75 \%$ by 2015. The National Policy on Skilled Birth Attendants 2006 aims to increase the percentage of births assisted by an SBA including expansion in the number of the training sites in the country to meet the required training needs. The main objective of the national policies on SBA was to reduce maternal morbidity and mortality by ensuring access to and utilisation of skilled care at every birth. ${ }^{11}$ The Second Long Term Health Plan1997-2017 has the goal of increasing the percentage of deliveries attended by trained personnel to $95 \% .{ }^{12}$ However there are several challenges to achieving this goal.

Delivery by SBAs serves as an indicator of achieving progress towards reducing maternal mortality worldwide, the fifth Millennium Development Goal. The proportion of deliveries assisted by a SBA has become an indicator for measuring maternal mortality reduction, including the three quarter reduction called for by the fifth MDG. ${ }^{13-}$ ${ }^{15}$ But increasing the coverage of delivery by skilled birth attendants (doctors, nurses or midwives) in developing regions has been slow. ${ }^{13}$

More than $80 \%$ of maternal deaths worldwide is due to five direct causes, haemorrhage, sepsis, unsafe abortion, obstructed labour and hypertensive diseases. ${ }^{16,2}$ Most of these deaths can be prevented if women have access to essential obstetric care during pregnancy. Approximately $61 \%$ of births in developing countries take place with the help of SBAs although this number varies by regions. ${ }^{15}$ In most cases, the lower the percentage of SBAs at delivery for country or region, the higher the lifetime risk of maternal mortality in that region or country4. A recent four-country (Benin, Ecuador, Jamaica and Rwanda) study has demonstrated that higher levels of skilled attendants during delivery lead to lower maternal mortality. ${ }^{17}$

It is estimated that, if there were SBAs at all deliveries, maternal mortality could be reduced by $13-33 \%{ }^{18}$ There are sound clinical reasons for a focus on skilled attendants. Globally, some $80 \%$ of maternal deaths are due to the direct obstetric complications but most could be prevented if women could access an SBA and necessary back up support around the birth and shortly thereafter. The remaining 20\% of deaths are due to indirect causes like severe Anaemia, Tuberculosis, Malaria and HIV/ AIDS. These also require the assistance of SBAs during pregnancy. ${ }^{19}$

According to NDHS (2006) 81\% of deliveries take place at home. ${ }^{8}$ Most births are assisted by family members, mainly a mother in-law and neighbours, though some women deliver alone8. Among the number of total births, one-fifth of deliveries are assisted by SBAs. ${ }^{8,9}$ However, in rural settings, and among some ethnics groups most women prefer to have a Traditional Birth Attendant (TBA) at the delivery. Pregnancy and child birth are still perceived as a natural phenomenon, not requiring formal health services. ${ }^{20}$

\section{Factors affecting uptake of SBAs in Nepal}

Several studies have reported that transportation and distance to the health facilities, staff attitudes towards service users, inadequate numbers of SBAs, Service delivery systems and poor physical infrastructure in 
the health facilities, women's age, parity and education, perceptions of safe pregnancy, place of residence (rural/ urban), gender inequality, cultural and religious beliefs, decision making power, socio economic status of women and geographical barriers including poor communication and road links are associated factors that affect the uptake of SBAs in Nepal. Studies not only indicate economic, geographic, cultural and religious factors but also salient institutional problems. This includes staff attrition for several reasons, limited availability of services, minimal staff support and training, lack of medicine and equipment and deficiency in the referral systems. ${ }^{19,21}$ It has also been suggested that political instability and weak governance often change policy and planning that all contributing use of existing health services. ${ }^{22}$ Here we discuss how these factors affect utilisation of SBAs during pregnancy on the basis of available literature.

\section{Transportation and distance to the facility}

Nepal's challenging terrain and poor communication network meant that travel to the facility is often difficult especially in the hill and mountain districts of Nepal. Poor or none-existent road links caused transport to be an important barrier. ${ }^{23,24,25}$ When travel times have to be measured in hours or even days rather than minutes because of the topography of the country (and most people travel without transportation), these become great deterrents to service use. ${ }^{26,27}$ Limited geographic access to maternal health services is a further barrier in the remote rural areas of Nepal. ${ }^{28,24} \mathrm{~A}$ period of armed conflict between the years of 1996-2006, further exacerbated the limited use of maternal health services. ${ }^{29}$ A study in 2003 found that the armed conflict had affected women's access to emergency obstetric care through increased barriers to travel and security. ${ }^{30}$ Studies from Afghanistan, Bangladesh, Malawi and Nepal have shown that living one hour away from a health facility increases the chance of a home delivery without a SBA eight times more than if the patient lived a distance of under one hour away from a health facility. ${ }^{31,32,23,33,34,35}$ Distance from a facility adds to the financial burden facing households through transport charges and time spent as well as other indirect cost for a delivery. ${ }^{36,23}$

\section{Staff attitudes towards service users}

Both positive and negative attitudes of staff play a part in the utilisation of SBAs in various ways. Staffs' positive attitude towards women during labour e.g. giving reassurance and encouragement and politeness encouraged use of SBAs. Studies from different developing country have shown that negative attitudes like rudeness, shouting during labour, lack of empathy, refusal to assist, and lack of moral support, making patients wait and giving priority on the basis of links to staff, caste and ethnic, language and religion all discourage use of SBAs. ${ }^{32,22}$ Similarly, a study from Nepal shows that too many outpatients in the departments of the facility make it difficult to manage privacy and confidentiality and lack of adequate training to service providers to maintain privacy and confidentiality also discourage use of SBAs. ${ }^{37}$

\section{Lack of skilled birth attendants}

Human resources are an important factor in health care. The evidence suggests that maternal mortality is responsive to the availability of skilled health workers. As in many developing countries, rural health services in Nepal are facing numerous problems that affect the uptake of SBAs. In Nepal there is a chronic shortage of skilled resources

e. g. the physician and nurse ratios are 5 and 26 per 100,000 people respectively. ${ }^{38}$ Lack of trained staff, equipment and drugs are common. ${ }^{22,25}$ Qualified midwives and doctors are often based in urban areas and/or hospitals4. A child from an urban area of Nepal is six times more likely to be delivered in a health facility with the help of an SBA than a child from a rural area. ${ }^{39}$ Pradhan et al 2010 shows that chronic shortages of skilled attendants in rural areas of Nepal due to frequent transfers of the staff, unfilled sanctioned posts, and staff on leave, high patient load and lack of female staff and poor facilities compared to urban areas. ${ }^{22}$ Different studies from Bangladesh, Malawi and Nepal show that death or retirement of staff, emigration overseas in search of better pay and working condition are further reasons for shortage of SBAs in many developing countries. ${ }^{4,22,32}$

\section{Service delivery systems and poor physical infrastructure in the facility}

In countries, like Nepal, low use of SBAs during pregnancy is not only caused by economic, geographic, cultural and religious reasons but also by institutional problems. Different research studies from Nepal have shown that poor quality services, unavailability and inaccessibility of services, minimal staff support, lack of medicine and equipment and deficiency in the referral systems are some reasons. ${ }^{40,19,20}$ Pradhan and colleagues mentioned in maternal morbidity and mortality study that staff knowledge and competence, lack of proper training and new development, inadequate payment, unsupportive management and lack of support from the other staff are some of the constraints on providing the quality maternal health services in Nepal. ${ }^{22}$ A Ghanaian study by D'Ambruoso and colleagues shows that other quality 
of care factors such as poor outcomes of the previous pregnancy, general environment of the facility e.g. level of noise, orderliness, water and light, sanitation, and privacy and inadequate number of staff are also related to the uptake of SBAs. ${ }^{41}$ Despite government efforts to improve the services; including the expanded network of maternal health clinics in rural areas and the training of Auxiliary nurse midwives (ANM) service use remains minimal. ${ }^{42}$ However, government health services are not the whole cause. A study conducted from Nepal shows that when illnesses occur, a range of local care providers are available. Health care choices are made within a network, depending on cost, geographical and climatic constrains, the time of day that labour occurs, and the types of illness or ethnic and religious concerns all play a vital role in the utilisation of SBAs in Nepal. ${ }^{43,31}$

\section{Women age, parity and education}

Younger women aged between 15 to 19 and those over 35 years, are at greater risk during childbirth. Available literature shows that women of 35 years and over who have more than three children are less likely to use SBAs during pregnancies. Different setting studies from Nepal have shown that the mother's education being lower than primary level and not having had antenatal care is also associated with a high prevalence of home delivery without help of SBAs. ${ }^{30,40,8,44,30,45,31}$ Low female literacy and women aged between 30-39 years were associated with the lower use of SBAs when compared to younger and literate women. ${ }^{33}$

\section{Perceptions of safer pregnancy}

It is reported that reasons for home delivery without help of SBAs in Nepal are poor maternal education, multi-parity and low socio economic status. Cost and convenience of health facilities are other factors affecting the utilisation of SBAs during delivery. ${ }^{46,30,31}$ Many women perceive pregnancy as normal phenomena so that it is not necessary to give birth in a facility with the help of SBAs; that 'it is not customary'; the facility is too far; or the baby was born before they could actually get to the facility. ${ }^{9}$ The assistance of SBAs during pregnancy also requires an understanding by the family and at a community level for their help to be used to maximum effect. Information about the reason for delivering at home without help of SBAs is also necessary for the policy and planning of appropriate maternity services. ${ }^{45}$ It is necessary for the mother and her family to understand different aspects of pregnancy and newborn care and to be prepared for potential danger signs. In most communities within Nepal, due to various reasons, there is little or no encouragement or support for women who have pregnancy complications to seek appropriate care. Furthermore, women as well as family members are often not aware of the life threatening danger signs of pregnancy or birth related complications. ${ }^{2}$

\section{Place of residence - rural/urban}

Maternal health care varies within and between developing countries around the world. A systematic review of inequalities in the use of maternal health care in developing countries mentioned that within countries, urban or wealthier women were more likely to deliver with the help of SBAs than rural and poor women were. ${ }^{47}$ In rural areas of Nepal, the proportion of institutional deliveries is as low as five times than urban areas. ${ }^{48,8}$ Though, in urban areas like Kathmandu a significant proportion of women still deliver at home. ${ }^{31}$ So, even easy access to institutional maternity services may not be enough to ensure the use of SBAs. There may still be access problems related to cost, attitude and beliefs of people. ${ }^{45,31}$ Studies from two rural districts of Nepal showed that a very large proportion of deliveries took place at home; only $6 \%$ of those deliveries were attended by SBAs. ${ }^{30}$

\section{Gender inequality}

It is widely accepted that increased gender equality is a prerequisite for achieving improvement in maternal health. In Nepal, past research has suggested that gender roles and relationships restrict women's use of SBAs during the pregnancy and at the time of delivery. ${ }^{45}$ Lack of freedom of movement and socialisation, education and economic dependency before and following marriage also force them to depend on their family and husband seek decisions from others on their own health care. ${ }^{49}$ Other factors include shyness or shame if there is male service provider, young women's lack of opportunity to discuss within the family, not having sufficient pregnancy related knowledge and decision making power, and young women's lack of influence over resources. ${ }^{22,39}$ A study from Pakistan shows that not involving male relatives (who are often the primary decision makers in family) and delay in seeking care all contribute to the low uptake of SBAs. ${ }^{50}$ Similarly, research in Nepal suggests that the availability of female SBAs at health facilities has a positive association with higher use of SBAs. ${ }^{22}$

\section{Cultural and religious belief towards pregnancy}

Nepal has an extremely diverse culture. The socio-cultural situation in Nepal also impacts negatively on requiring 
the assistance of SBAs during pregnancy. Some cultural and religious practices in Nepal, mostly in remote and rural areas, prevent women from accessing and utilizing essential heath care services such as 10 days after child birth are considered to be impure and during that period, the women were secluded from the family members. ${ }^{2}$ For example, women not being allowed to cross rivers, a belief in ghosts or witchcraft prevent health care during pregnancy. ${ }^{22}$ Following marriage, a daughter- in-law is expected to perform domestic duties under the supervision of her mother- in- law, who is usually the primary decision maker in matters of child-rearing and care of the family. ${ }^{51}$ The low status of women, poverty and the so-called caste system also prohibit women from obtaining maternal health services. In Nepal, research shows that Hindu higher castes (Brahmins, Chhetri and Newars) are more likely to deliver at a health facility attended by SBAs than others. ${ }^{52}$ Similarly, in Bangladesh Muslim women made less use of SBAs compared to other religious groups during pregnancy. ${ }^{34}$

\section{Decision making power}

Nepalese society is predominantly patriarchal and men are the primary decision makers in most Nepalese families. Women lag far behind men in education, economic resources, opportunities, and involvement in non-agricultural activities. ${ }^{42}$ A recent study in Nepal by Acharya and colleagues has shown that women's decision making for health care is directly associated with age; ethnicity; residence type (rural/urban); level of deprivation; education level; job; and number of living children ${ }^{53}$. Previous research studies in Nepal have shown that those women who completed at least a primary level of education and who have been involved in employment outside of their home are more likely to be involved in decision making..$^{45,54,40}$ A qualitative study from Nepal by Simkhada and colleagues suggests that the mother-in-law and other family members have significant influence over decisions regarding uptake of maternal health care. ${ }^{55}$

\section{Socio-economic status of women}

In general, women with low statuses are less likely to use modern facilities, whereas women with higher statuses take the initiative in seeking care for themselves and for their children. ${ }^{56}$ The population of Nepal have limited resources; poor communication system and less involvement of women in media particularly in rural and remote areas, low life expectancy, low adult literacy rates, high fertility rates, early and almost universal marriage rate, high rates of adolescent pregnancy and high rural concentration are common characteristics affecting Nepalese women. ${ }^{57}$ Studies show that there are close links between the indicators of women's status in society; education; income; power over resources household position; reproductive health awareness; and uptake of SBAs for delivery. ${ }^{45}$ However, very few of these issues have been examined how and why they are related to using SBAs for delivery in Nepal. The affordability of obstetric health services is a further determinant of care seeking behaviour in many developing countries. Evidence from sub-Saharan Africa and South Asia indicates that households often spend significant amounts for delivery care especially if complications arise. ${ }^{58}$

\section{CONCLUSIONS}

It has been found that different socio cultural, religious, financial and demographic factors have a significant role for uptake of SBAs for delivery. Available literature shows that there is very little known about how and why these determinants are responsible for the uptake of skilled birth attendants for delivery. As a result, there are methodological gaps in exploring women's choices and issues on using maternal health services. Numerical findings alone are not sufficient for real and effective improvements for maternal health.

The majority of women in Nepal still continue to deliver babies in their own community without the help of SBAs. It is known that from the literature review utilisation of the maternal health services is influenced by the characteristics of the available health system, such as quality of services, cost, conveniences, accessibility and availability of services and its use. Characteristics of the health delivery system are not the only explanatory factors in addressing the women's choices in uptake of maternity care services. Other factors such as the socio-cultural and religious structure of the communities and characteristics of the individual should also be considered in promoting the utilisation of effective maternal health services. Maternity health care is a choice and depends on individuals but literature suggests that choices are limited especially in the mountain and hill areas of Nepal. Communities, family members and women must all be taught the difference and benefit SBA services bring to maternal healthcare. Thus, it is necessary to do more qualitative research to address the issues and problems for developing appropriate health care services for uptake of SBAs for delivery. 


\section{REFERENCES}

1. Simkhada PP, Baral YR, van Teijlingen ER. Health and medical research in Nepal: a bibliometric review. Asia Pac J Public Health 2010; 22:492-500.

2. WHO. Making pregnancy safer: the critical role of the skilled attendant. A joint statement by WHO, ICM and FIGO. Department of Reproductive Health and Research. WHO, Geneva. 2004.

3. WHO. The WHO and the Millennium Development Goals. Fact sheet no. 290. World Health Organization, Geneva. 2005.

4. Carlough M, McCall M. Skilled birth attendance: What does it mean and how can it be measured? A clinical skills assessment of maternal and child health workers in Nepal. Int J Gynaecol Obstet 2005;89:200-208.

5. WHO. Proportion of births attended by a skilled health worker. 2008; [cited 2010 Aug 11]. Available from: www. who.int/reproductive_health/global_monitoring/data. html

6. WHO. Maternal mortality in 2005: estimates developed by WHO, UNICEF, UNFPA and World Bank. World Health Organization, Geneva. 2007.

7. WHO Neonatal and perinatal mortality - country, regional and global estimate 2004.Geneva, World Health Organization; 2006 [cited August 2010 Aug 5]. Available from: www.who.int/reproductive_health/docs/ neonatal_perinatal_mortality/index.html

8. NDHS. Nepal Demographic and Health Survey. Nepal Ministry of Health. New Era and ORC Macro, Calverton, MD, USA; 2006.

9. Pant PD, Suvedi, BK, Pradhan A, Hulton L, Matthews Z, Maskey $M$. Investigating recent improvements in maternal health in Nepal: Further Analysis of the 2006 Nepal Demographic and Health Survey. Calverton, Maryland, USA: Macro International Inc. 2008.

10. MoHP. National In -Service Training Strategy for Skilled Birth Attendants 2006-2012. National Health Training Centre, Ministry of Health and population, Nepal. 2007

11. Devkota M, Putney P. Support to Safe Motherhood Programme, Nepal. A part of HMGN Nepal National Safe Motherhood Programme (NNSMP). Reducing Consensus on a Minimum Package of MHN Services. Increasing Access to Essential Care for the Mothers, Newborn and Children in Nepal, 630/04/DFID. 2005.

12. AbouZahr C, Wardlaw T. Maternal mortality at the end of a decade: signs of progress? Bull World Health Org 2001; 79:561-568.

13. Koblinsky M, Matthews Z, Hussein J, Mavalankar D, Mridha MK, Anwar I, et al. Going to scale with professional skilled care. Lancet 2006;368:1377-86.
14. Harvey SA, Blandon Y, Binns A, Sandino L. Urbina L, Rodriguez $\mathrm{C}$, et al. Are skilled birth attendants really skilled? A measurement method, some distributing results and a potential way forward. Bull World Health Org 2007; 85:783-90.

15. UN. End Poverty 2015 makes it happen. Millennium Development Goals Fact Sheet. United Nation Headquarter, New York. 2008.

16. Harvey SA, Ayabaca P. Bucagu M, Djibrina S, Edson WN, Gbangbade S, et al. Skilled birth attendant competence: an initial assessment in four countries, and implications for the safe motherhood movement. Int J Gynecol Obstet 2004;87:203-10.

17. Graham W, Bell JS, Bullough CHW. Can skilled attendances at delivery reduce maternal mortality in developing countries? Stud HSO 'P 2001;17:97-129.

18. Bernis L, Sherratt DR, Abouzahr C, Van Lerberghe W . Skilled attendants for pregnancy and postnatal care. Brit Med Bull 2003; 67:39-57.

19. UNICEF. Skilled Care during Child Birth Policy Review 1998. [cited 2010 July 3] Available from: http://www. whiteribbonalliance.org/Resources/Documents / Skilled\%20Care\%20During\%20Childbirth_Policy\%20 Brief_Family\%20Care\%20InternationalInc.pdf

20. Ratnaike R, O’Neil P, Chynoweth R. Village health workers and malnutrition: a project that failed. World Health Forum 1984;5:316-8.

21. Kaufmann D, Kraay A, Mastruzzi M. Governance matters VII: Aggregate and individual governance indicators, 1996-2007. In World Bank Policy Research Working Paper No 4654 Washington DC: World Bank. 2008.

22. Pradhan A, Subedi BK, Barnett S, Sharma SK, Puri M, Paudel P, et al . Nepal Maternal Morbidity and Mortality study 2008/2009. Family Health Division, Department of Health Services, Ministry of Health and Population, Kathmandu, Nepal, 2010.

23. Borghi J, Ensor T, Neupane BD, Tiwari S. Financial implications of skilled birth attendance at delivery in Nepal. Trop M Int Health 2006; 2(II) 228-237.

24. Simkhada B, van Teijlingen ER, Porter M, Simkhada P. Major problems and key issues in Maternal Health in Nepal. Kathmandu Univ Med J 2006;4:258-63.

25. Acharya LB, Cleland J. Maternal and child health services in rural Nepal: does access or quality matter. Health $\mathrm{Pol}$ Plan 2000; 15:223-9.

26. Hotchkiss DR. Expansion of rural health care and the use of maternal services of Nepal. Health Place 2001;7:39-45.

27. Furber AS. Referral to hospital in Nepal: 4 years experience in one rural district. Trop Doct 2002;32:75-8. 
28. Rath DA, Basnet I, Cole M, Subedi HN, Thomas D, Murray SF. Improving Emergency Obstetric Care in a Context of Very High Maternal Mortality: The Safer Motherhood Project 1997-2004. Reprod Health Matter 2007; 15:72-80.

29. Thapa D. A Kingdom under siege: Nepal's Maoist Insurgency, 1996-2003. The print house, Kathmandu, Nepal. 2003.

30. Wagle RR, Sabroe S, Nielsen BB. Socioeconomic and physical distance to the maternity hospital as predictors for place of delivery: an observation study from Nepal. BMC Pregnancy Childbirth 2004;4:8.

31. Bolam A, Manandhar DS, Shrestha P, Ellis M, Malla K, Costello AM. Factors affecting home delivery in the Kathmandu valley, Nepal. Health P Plan 1998;13:152158.

32. Kamwendo LA, Bullough C. Insights on skilled attendance at birth in Malawi-The findings of a structured documents and literature review. Malawi Med J 2005; 16:40-2.

33. Mayhew M, Hansen PM, Peter DH, Edward A, Singh PL, Dwivedi $\mathrm{V}$, et al. Determinants of skilled birth attendants utilisation in Afghanistan. A cross sectional study. Am J Public Health 2008;98:1849-185.

34. Anwar I, Sami M, Akhtar N, Chowdhury ME, Salma $\mathrm{U}$, Rahman $\mathrm{M}$, et al. Inequity in maternal health-care services: evidence from home-based skilled-birthattendant programmes in Bangladesh. Bull World Health Org 2008;86:252-9.

35. Koblinsky M, Anwar I, Mridha MK, Chowdhary ME, Botlero R. Reducing Maternal Mortality and Improving Maternal Health: Bangladesh and MDG 5. J Health Pop Nutr 2008;26:280-94.

36. Sharma S. Reproductive Rights of Nepalese Women: Current status and future directions. Kathmandu Univ Med J 2004;2:52-4.

37. Hongoro C, Mc Pake B. How to bridge the gap in human resources for health. Lancet 2004;364:1451-6.

38. Pradhan A. Situation of antenatal care and delivery practices. Kathmandu Univ Med J 2005; 3:266-70.

39. Matsumura M, Gubhaju B. Women's status, household structure and the utilisation of maternal health services in Nepal. Asia Pac Pop J 2001; 16:23-44.

40. D’Ambruos L, Abbey M, Hussein J. Please understand when I cry out in pain: women's accounts of maternity services during labour and delivery in Ghana. BMC Public Health. 2005;5:140.

41. A D B. Woman in Nepal, country brief paper. Kathmandu, Nepal; 1999.
42. Mesko N, Osrin D, Tamang S, Shrestha BP, Manadhar DS, Manandhar M, et al . Care for perinatal illness in rural Nepal: a descriptive study with cross sectional and qualitative components. BMC Intl Health Human Rights 2003;3:3.

43. Simkhada B, van Teijlingen ER, Porter M, Simkhada P. Factors affecting the utilisation of antenatal care in developing countries: systematic review of the literature. J Advanc Nurs 2008;61:244-60.

44. Furuta M, Salway S. Women's position within the household as a determinant of maternal health care use in Nepal. Int Fam Plann Perspect 2006;32:17-27.

45. Sreeramareddy TC, Joshi SH, Sreekumaran VB, Giri S, Chuni N. Home delivery and newborn care practices among urban women in western Nepal: a questionnaire survey. BMC Pregnancy Childbirth 2006; 6:27.

46. Say L, Raine R. A systematic review of inequality in the use of maternal health care in developing countries: examining the scale of the problem and the importance of context. Bull World Health Org 2007;85:812-9.

47. MoH. Annual Health Report-2004. His Majesty Government, Nepal; 2004.

48. Acharya PP, Rimal D. Pregnancy and childbirth in Nepal: women's role and decision making power. Selin. H. (Ed), Childbirth across cultures, science across the cultures: The history of non-western science, 5. Springer Science and Business Media . 2009

49. Mumtaz Z, Salway S. Gender, pregnancy and uptake of antenatal care services in Pakistan. Sociol Health Illness 2007; 29:1-26.

50. Dali SM, Thapa M, Shrestha S. Education for Nepalese women to provide improved care for their childbearing daughters-in-law. World Health Forum 1999;13:353-4.

51. Osrin D, Tumbahangphe KM, Shrestha D, Mesko N, Shrestha BP, Manandhar MK, et al. Cross sectional, community based study of care of newborn infants in Nepal. Brit Med J 2002;325:1063-6.

52. Acharya DR, Bell JS, Simkhada P, van Teijlingen ER, Regmi PR. Women's autonomy in decision- making: a demographic study in Nepal. Reprod Health 2010;7:15.

53. Hatt L, Stanton C, Makowiecka K, Adisasmita A, Achadic E, Ronsmansb C. Did the strategy of skilled attendance at birth reach the poor in Indonesia? Bull World Health Org 2007; 85:774-782.

54. Simkhada B, Porter MA, van Teijlingen ER. The Role of mothers-in- law in antenatal care decision making in Nepal: a qualitative study. BMC Pregnancy Childbirth 2010;10:34. 
55. Caldwell B. The family and demographic change in Sri Lanka. Health Tram Rev 1996; 6:45-60.

56. Pradhan A, Aryal R, Regmi G, Ban B, Govindasamy P. Nepal family health survey 1996. Kathmandu, Ministry of Health, Nepal; New ERA; Macro International. 1997.
57. Nahar S, Costello A. The hidden cost of 'free' maternity care in Dhaka, Bangladesh. Health Pol Plann 1998; 13: 417-22.

58. Levin A, McEuen M, Dymatraczenko T, Sengooba F, Mangani R, Dyck VG. Costs of Maternal Health care Services in three Anglophone African Countries. Special Initiatives Report 22, Partnerships of Health Reform, Abt Associates, Bethesda, 2000. 